\title{
Gestão de Cidades Históricas para o Turismo: questões teóricas e práticas
}

\author{
Historical Cities Manasement for Tourism: \\ theoretical and practical issues
}

Mário Jorge Pires'

RESUMO: O presente artigo trata de algumas questōes teóricas concernentes ao ato de tombamento e às polêmicas que ele costuma gerar, levandose em conta que a administração municipal possui responsabilidade sobre a gestão do patrimônio histórico-cultural. Questōes de ordem prática também são abordadas, mormente aquelas em que o município tem o dever de conciliar os interesses dos moradores com as imposiçōes resultantes de ser guardião de recursos culturais.

PALAVRAS-CHAVE: turismo cultural; gestão de cidades históricas; patrimônio cultural; tombamento.

ABSTRACT: This paper examines some theoretical issues concerning preservation and controversies about this action has been used to created, taking into consideration that the public administration has the responsibility of management heritage properties. Practical issues are also approached, as well as those relating to the obligation of public sector about conciliate resident's interests and impositions resulting from safeguard cultural resources.

KEYWORDS: cultural tourism; historical cities management; cultural property; preservation.

1. Doutor em Turismo pela ECA-USP, professor dos cursos de graduaçāo e pós-graduaçāo da mesma instituição e articulista do jornal O Estado de S. Paulo. Contato: Av. Prof. Lúcio M. Rodrigues, 443 Bloco B - 05508-900 - São Paulo-SP; e-mail: majortur@bol.com.br 


\section{Introdução}

Antes de qualquer esboço de ações práticas em cidades históricas, convém apontar as questões levantadas por alguns especialistas quanto à validade de se ter "cidades históricas", e se esta expressão é, de fato, um eufemismo que visa camuflar um suposto congelamento de uma cidade, tornando-a artificial e fadando seus moradores à não-mudança.

A preservação, cujo ato é o tombamento, é um recurso usado na grande maioria dos países do mundo. Objetiva resguardar as culturas material e imaterial dotadas não apenas de pretenso valor histórico de determinado grupo social, mas, sobretudo, aquelas carregadas de valor simbólico, por diferentes motivos. Então, preservar não é congelar, é um ato de autodefesa grupal que faz frente a uma dinâmica deterioradora de valores, de símbolos, de ritos e até de mitos. Por que não?

Então, o tombamento, em princípio, é uma atitude válida. Não se trata de cristalizar o passado e o presente, como criticam alguns, determinando, ao mesmo tempo, o presente das gerações futuras. Atitudes preservacionistas são ações de resistência à atual noção de tempo, principalmente ao paradigma de que "tudo está em rápida transição", por isso, nada vale, uma vez que hoje é assim, amanhã não será mais.

Corroborando com o que foi dito, existem pelo menos dois grandes argumentos a favor do tombamento. $O$ primeiro, de ordem genérica e de interesse para toda a humanidade, o outro, importante para cada morador de cidade e que deveria constar do guia de qualquer planejador urbano. São eles: o mundo não poderá criar seus espaços urbanos a cada geração, pois não há recursos na natureza para tanto, então preservar é um ato de economia, em última instância, de recursos naturais; em segundo lugar, a cidade possui componentes que a tornam um ícone, ou uma unidade compreensível para cada morador, responsável pela manutenção da identidade e singularidade do local. Assim, a cidade, como fenômeno cultural, deve ser tratada "em seu funcionamento, de artifício significante" (Eco, 1976: 22). Mudanças ao sabor do apetite econômico de cada geração devem ser pensadas.

Posto isso, qualquer planejamento urbano deve ter presente a possibilidade de contar com tombamentos. Estes não são males necessários, ao contrário, além dos benefícios à identidade local, podem integrar o conjunto de atrativos turísticos da cidade. Aliás, uma cidade tombada e, por isso, histórica, representa, por si só, um grande atrativo para o turismo, levando-se em conta o conjunto formador de uma atmosfera diferenciada.
A gestão de cidades históricas representa um verdadeiro desafio ao administrador público que, além dos problemas oriundos de qualquer cidade normal, ainda conta, por um lado, com restrições no que se refere a intervenções físicas nos núcleos históricos, por outro, com dificuldades de fiscalização do gabarito histórico e em conciliar os interesses dos moradores com os dos visitantes. Neste caso, a cultura política brasileira não é uma grande aliada dos gestores, mas, em contrapartida, estão ganhando realce as gestões participativas para chegar às questões de ordem prática.

\section{Cultura Política do Cabo-de-Guerra}

Não é desconhecido do brasileiro médio comum e relativamente bem informado que a política norteia-se pelo imediatismo. Entre optar por benefícios de médio e longo prazos ou por aqueles que cabem exatamente no período de tempo de uma administração, a resposta é óbvia. Por isso, não são todos os políticos que gostam verdadeiramente da atividade turística, uma vez que, tomada essa posição, raramente os frutos serão colhidos na mesma administração. Plantar para o sucessor colher, isso é impensável na cultura política brasileira. Claro que aqui se excluem as medidas meramente cosméticas que costumam dar a impressão de que a prefeitura está fazendo algo para o crescimento municipal do turismo, ou os casos em que o prefeito faz seu sucessor.

O que é interessante para a cidade não o é, necessariamente, para os políticos. A instalação de uma grande indústria em um município cuja cidade é histórica costuma gerar menos emprego do que o turismo, entretanto, esses empregos são criados rapidamente, na mesma gestão. Além desse benefício, tem um outro, também bem conhecido: uma grande empresa pode financiar campanhas políticas, pode fazer o famigerado jogo da eleição de prepostos para seus interesses. A atividade turística pulveriza a arrecadação e a política, é mais difícil controlar um grande número de pequenos empresários do que uma única e grande indústria, ou um pólo industrial que seja, uma vez que os interesses dos que o compõe são os mesmos.

Assim sendo, qual é a opção mais desejada pelos políticos?

Caso bem documentado é o de Ouro Preto-MG, em que a prefeita declarou que os interesses na cidade estavam muito mais voltados para a mineração do que para o turismo, posto que este último entrava com apenas $5 \%$ da arrecadação do município. Entretanto, em dez anos, a indústria de alumínio lá instalada diminuiu em $70 \%$ a sua mão-de-obra, ao passo que os empregos em turismo, no 
mesmo período, aumentaram em $300 \%$ (Pires, 2002). É de pasmar que, mesmo com esses dados, a edilidade ainda opte pela mineração.

Administrar uma cidade histórica exige muito conhecimento do assunto e uma grande dose de pulso firme. É um trabalho perpétuo de educação do munícipe e de criação de soluções adaptadas às peculiaridades da cidade. As ações devem contemplar diuturnamente a educação patrimonial, de forma que o morador tenha orgulho da sua casa histórica pertencente ao conjunto. Isso é fácil de falar e difícil de fazer, uma vez que o habitante deseja ter todos os confortos do século XXI. Sem o orgulho e a questão pecuniária - vale dizer, ganhar dinheiro para a sua sobrevivência - fica difícil convencer o morador de que ele não pode abrir um buraco em uma parede de 250 anos de sua casa para construir uma garagem. Isso não significa, entretanto, que todo o habitante terá sua renda diretamente no turismo, mas - ponto fundamental de esclarecimento municipal - que o turismo tem um efeito multiplicador, gerando oportunidades em setores cuja conexão com o turismo nem sempre é tão visível.

Então, em uma cidade histórica, com um turismo se estabelecendo, a tentação à demagogia costuma ser grande. Se em Parati-RJ ruas foram fechadas ao trânsito de carros, em Ouro Preto eles circulam livremente por toda a cidade, mesmo porque a topografia não é nem um pouco convidativa a se andar em todo o lugar a pé. Mas, algumas medidas poderiam ser tomadas, como a proibição de automóveis e veículos de grande porte na Praça Tiradentes - ponto central da cidade - e em ruas muito estreitas. Isso, porém, é comprar briga com uma parcela da população. O imediatismo político mais uma vez brada: morador vota, turista não.

Existem vereadores e prefeitos com maior consciência e visão, mas o comum é o exercício da política cabo-de-guerra. Esta se resume no seguinte: como derrotar os adversários políticos sempre é mais importante do que o bem maior, do que aquilo que deve ser melhor para o município, então, em muitas ocasiões, metade dos políticos puxam a corda numa direção e a outra metade noutra. Como resultado, a cidade fica paralisada e medidas urgentes deixam de ser tomadas. Pode-se dizer, sem exagero, que o jogo político dentro da tradição local brasileira é tão auto-suficiente que nem precisa de município, adquire autonomia própria.

A gestão de cidades históricas entra também na política do cabo-de-guerra quando o assunto é tombamento. Uma vez que este se processa nas esferas estadual ou federal, não há muito em que se possa opinar a respeito. Porém, muitas destas cidades promovem o tombamento municipal na tentativa de preservar o patrimônio histórico-cultural da localidade. Esta atribuição é assegurada pela Constituição da República, na qual o artigo número 30, IX, reza como compe- tência também dos municípios "promover a proteção do patrimônio históricocultural local, observada a legislação e a ação fiscalizadora federal e estadual" (Constituição da República, 1988). O tombamento mexe com interesses de especulação imobiliária, amiúde de gente poderosa, com influência e dinheiro suficientes para produzir agitação política na câmara. Comprar esta briga não exige apenas coragem. Antes de tudo, vale a pena reafirmar a necessidade de se ter uma política clara de gestão desses recursos inserida no planejamento municipal.

Isso tudo pode não funcionar se não houver uma estratégia de gestão. Ter tudo no papel não garante maioria na câmara tampouco anula a política do cabode-guerra. Uma saída possível seria a "gestão participativa" que reuniria representantes elideranças de diferentes setores do município em uma câmara informal. Esta deve ter como princípios prioritários o compromisso de tirar de seus encontros decisões claras (ao contrário do cabo-de-guerra) e de atuar como detentor de pressão pública. Como isso, ações corajosas por parte do executivo ganham respaldo.

\section{Questões de Ordem Prática}

Embora seja o turismo uma fonte importante na geração de empregos e de recursos públicos, o patrimônio histórico-cultural não pode estar meramente subordinado às leis de mercado. Este não deve ser soberano nem ditar as regras do espaço público, pois isso seria a banalização da cultura, assunto tão criticado pelos filósofos. Em uma cidade histórica, algumas regras acabam sendo fundamentais para uma boa convivência entre moradores e turistas, entre espaço público tombado e espaço do munícipe. As principais regras são as seguintes:

1. Adros das igrejas. Devem permanecer constantemente abertos, pois são espaços de usufruto da população local e, no caso de cidades históricas do período colonial, fazem às vezes de praça pública, posto que estas cidades caracterizam-se pela ausência de praças. Pode-se dizer que os adros funcionam como espaços multifuncionais: garotos empinam pipa no adro da Igreja das Mercês dos Perdões, em Ouro Preto; casais namoram no da Capela do Padre Faria, por que não?; turistas descansam sentados nas grossas muralhas do adro da Igreja de São Francisco de Assis. Todas elas em Ouro Preto. A população necessita sentir que estes espaços não são exclusivamente reservados aos turistas, por isso, gradear adros com porteiras e cadeados não é uma boa opção. Argumenta-se que, fechando-os à noite, evitam-se assaltos, vandalismo contra o bem histórico e cenas obscenas à vista de todos. Adros bem iluminados, com vigilante municipal em cada um, como haveria em uma praça normal, conseguem transformar estes 
locais em espaços vivos, ao contrário do que são hoje. Custos? Menores do que os da manutenção de praças, além do que podem ser estabelecidas parcerias com a iniciativa privada.

2. Becos e ruas muito estreitas. Não só a largura das ruas era diferente nos períodos colonial e monárquico, mas a própria malha urbana, responsável pelo razoável número de becos estreitos para os padrões de hoje. Estes representam um problema - costumam ligar duas ruas importantes, relativamente paralelas pois ainda nos dias de hoje são usadas pela população residente. À noite, costumam estar desertos e com iluminação precária. Com o aumento da violência, algumas cidades resolveram bloquear o acesso a estes becos assim que escurece o dia. De novo fez-se uso do gradeado, criando no conjunto histórico mais uma anomalia. Nas cidades brasileiras, históricas ou não, o comum é a prefeitura optar pela solução mais fácil, sem pensar nas conseqüências que as ações podem ter na dinâmica delas. Se esses espaços ainda possuem um uso primordial e é usado pela população, em princípio jamais deveriam ser fechados, porém deveriam receber iluminação especial. Bloquear o acesso à noite está na contramão do que é praticado em muitas cidades históricas da Europa. Imagine-se, aqui, se cada cidade medieval e, portanto, repleta de becos, resolvesse fechá-los à noite. Não se poderia transitar e sequer haveria turismo nelas. O medo da delinqüência não pode ser a mola propulsora para as ações de inércia, como o fechar, o bloquear acessos descaracterizando o patrimônio, o passar à chave toda a cidade, achando que assim a criminalidade vai diminuir.

3. Lixeiras. Em cidades históricas as lixeiras jamais deveriam estar em frente aos monumentos ou, de qualquer maneira, provocar um efeito destoante ao lado de cada bem histórico. Em Salvador, do lado da porta da Igreja do Carmo, embaixo de uma placa que narra a rendição dos holandeses naquele local, havia uma lixeira de plástico amarela segura por uma haste. Visão entristecedora. Em Ouro Preto, no chafariz histórico, ao lado da casa do inconfidente Cláudio Manoel da Costa, uma lixeira de metal pequena, cintilante de parca funcionalidade e, como de resto, em quase toda a cidade, colocada em local despropositado. Em cidades históricas no exterior, usam-se barricas pintadas ou decoradas com motivos regionais. O mesmo podia ocorrer nas cidades históricas brasileiras. Em Ouro Preto, por exemplo, por que não usar barricas decoradas com folhas de acanto ou pinturas que remetessem ao século XVIII? Por que não seriam autênticas? Os puristas que assim pensam deveriam estudar um pouco teoria da comunicação e semiologia, ao invés de tecerem comentários irreais e arrogantes.
4. Placas e sinalização de trânsito. Quem acompanhou a trajetória de preservação do patrimônio histórico brasileiro sabe quão árdua luta foi a de convencer os comerciantes a tirar grandes tabuletas das portas das lojas em edificações históricas. Agora, passada esta epopéia, a tecnocracia padronizou as placas de sinalização de trânsito. Isso é bom, mas não para uma cidade histórica. Em Ouro Preto, nas ruas centrais do miolo do núcleo histórico há uma placa de trânsito a cada 25 metros, aproximadamente. Quem de longe olhar a rua Conde de Bobadela verá a horrível poluição visual das placas. Desnecessário dizer que esta sinalização deveria estar em sintonia com a atmosfera da cidade. Em cidades alemãs isso já acontece e, no nosso caso, as soluções criativas deveriam sair da própria localidade. Não haver sinalização de trânsito em frente a chafarizes históricos parece um tanto óbvio, mas em Ouro Preto, infelizmente, esta é a regra.

5. Shows em praças históricas. Deve-se dizer, a bem da verdade, que esse problema não é exclusivamente brasileiro. Além de todos os transtornos causados pelas águas, Veneza sofre com megashows na praça histórica (Borg, 2001). Milhares de decibéis ao lado das antigas e frágeis estruturas do passado configuram-se como uma grande irresponsabilidade. Em Ouro Preto são comuns os shows na Praça Tiradentes. A desculpa é sempre a mesma: os moradores precisam de diversão. Porém, não se cogitam os benefícios de uma descentralização, que seria colocar esses shows e outros eventos com milhares de pessoas em um outro lugar. Isso teria efeito positivo sobre o comércio desses novos lugares, além do incremento dos recursos turísticos sub-utilizados da área periférica (Boniface, 1995).

6. Ocupação do entorno de uma cidade histórica. Ao contrário do que seria deixar uma cidade à deriva, o planejamento mais uma vez faz-se necessário. Bairros novos devem ser planejados pela edilidade, tanto em áreas planas como na morraria. Em Ouro Preto, ao lado da Igreja de Santa Ifigênia o morro que serve de moldura à cidade está sendo ocupado por um novo bairro, em verdadeiro escárnio aos órgãos de proteção ao patrimônio e à prefeitura, além de ter a agravante de se encontrar em área de risco no período das chuvas. O crescimento da cidade se faz contornando morros, não os escalando e destruindo áreas de proteção. Política habitacional deveria ser um item obrigatório em um plano diretor, reservando parte da arrecadação do turismo para tal finalidade. Mais do que isso: um pólo industrial acha não possuir responsabilidade alguma sobre a margem de periferia que ele gera, e nem um centavo da sua arrecadação vai para minimizar tal problema. Muitos especialistas deveriam pensar nisso antes de criticar o turismo como responsável pela degradação de uma cidade. 
seria o portal como pedágio, no qual o turista recebe meia dúzia de folhetos sobre

7. Trânsito pesado na malha histórica. Ruas que surgiram e mantiveram-se como nos séculos XVII, XVIII ou XIX são absolutamente impróprias para grandes e pesados veículos. Quando se vê grandes coletivos manobrarem a alguns centímetros apenas do Palácio dos Governadores, em Ouro Preto, ou um grande caminhão perdendo os freios na ladeira e destruindo um chafariz secular, pensase a quem interessa o trânsito desses veículos senão, exclusivamente, à ganância de seus proprietários e à demagogia beneplácita dos órgãos reguladores desse tipo de atividade no núcleo histórico. No Brasil inteiro já se provou que vans e microônibus são rentáveis, que caminhões de pequeno porte e pick-ups já se fazem presentes com grandes vantagens e que, portanto, devem ser usados nos locais em questão.

8. Piscinas e fiação elétrica. Edificações históricas, monumentos, o traçado das ruas, tudo, enfim, contribui para uma harmonia do conjunto. $\mathrm{O}$ que mais fascina o visitante em uma cidade histórica é a atmosfera de volta ao passado, experiência sofrida com grande satisfação em oposição ao cotidiano monótono e previsível, vivido em uma grande cidade moderna. O estar e o caminhar por ruas coloniais ou imperiais preenchem a ânsia de evasão do turista, desde que o conjunto consiga manter a atmosfera de outro tempo. Quer, assim, o bom senso que todas as iniciativas objetivando manter essa integridade recebam grande atenção e cuidados especiais. As piscinas a céu aberto, que podem ser vistas a partir de ruas em patamares mais elevados na cidade, representam uma anomalia a ser abolida. Não significa, entretanto, que a população deva privar-se desse conforto moderno, mas camuflá-las com coberturas de capa-e-canal ou vegetação, de forma a não serem vistas, isso representaria um grande benefício para o conjunto histórico. Do mesmo modo surpreende, negativamente, a existência de postes com emaranhada fiação elétrica tão próximos à Praça Tiradentes, em Ouro Preto. Felizmente, boa parte das cidades históricas brasileiras é sensível a este assunto. Merecem elogios as galerias especiais em São Luís - MA, onde foi colocada toda fiação debaixo do solo.

9. Portal de ingresso à cidade. Propositalmente está como o último item deste artigo, pois é um assunto que, por ser polêmico, exige uma reflexão mais acurada. Não se trata de bloquear o acesso à cidade, uma vez que um portal deve ter como filosofia dar as boas vindas aos visitantes. Como? Informando, cativando, conscientizando. Um bom portal deve expressar todo o orgulho que a cidade despendeu trabalhando para que o visitante tenha uma estada prazerosa, mas sem esquecer os itens relacionados a educar o turista. $\mathrm{O}$ oposto desta filosofia os atrativos da cidade e pode usar um banheiro de higiene duvidosa. Não é isso. Velho ditado recomenda: "se fores a Roma, habitue-se aos costumes romanos". Multimídia, palestra, seja o que for, a finalidade é mostrar que o turista é bemvindo, mas a cidade tem suas regras - e tradições. Quais são os locais em que se pode transitar de carro e estacionar? Como são as placas de sinalização de trânsito? Quais as roupas e o comportamento adequados para visitar igrejas que, em última instância, ainda possuem sua função religiosa inalterada para o morador? Entrar de boné na igreja ou com roupas que cairiam melhor se o ambiente fosse uma praia são atos extremamente ofensivos à população local. Educação do turista é respeitar o morador, seus hábitos, suas crenças, suas tradições. A dedução mais óbvia desse item é que, se a cidade não despender esforços de forma a mostrar ao visitante que ela está tentando acertar - com ações concretas, trabalhando com o munícipe a educação patrimonial e desenvolvendo em cada um o orgulho de morar em uma cidade histórica -, o portal será um embuste ou um arremedo de modernidade, mais dinheiro público jogado fora, uma atitude antipática e cínica na proporção em que se está exigindo muito do visitante e pouco da administração pública.

\section{Considerações Finais}

A arrecadação municipal a partir do turismo está longe de ser a única finalidade de se optar por este tipo de atividade. $O$ mercado não pode ser o grande ditador de todos os recursos e nem o patrimônio histórico-cultural ser subserviente a ele. Entretanto, afirmar que turismo nada tem a ver com princípios e práticas pedagógicas é um erro comum entre os museólogos: expressa uma visão obsoleta e bastante equivocada, pois ele é um grande instrumento de pedagogia informal na era das múltiplas possibilidades que se têm à disposição para a prática do lazer ativo. Para isso, é necessário que ambos os profissionais mudem, tanto o defensor do patrimônio, com visão conservadora, purista e, em grande parte, irreal, que acha que o turismo só destrói, quanto o turismólogo, para quem o mercado é um deus, merecedor de apologia e acirrada defesa. Então, o turismo é gerador de emprego e riqueza, mas, principalmente, uma ferramenta de democratização da cultura, por isso não deve nem pode receber a censura da elite intelectual.

Questões como a liberação dos adros, iluminação dos becos, uso de microônibus e caminhões de pequeno porte e orquestração do trânsito, estão longe de 
ser sugestões irreais, pois estas ações deram certo em várias localidades turísticas. Além disso, só fazem contribuir para o aumento da qualidade de vida do morador.

Os itens gerais de gestão estão de tal ordem amalgamados ao trabalho de melhoria do produto que apenas didaticamente pode-se separá-los como coisas distintas. A efetiva utilização turística e os retornos benéficos advindos desse setor exigem da municipalidade muito mais do que deixar a cidade apresentável e com facilidades e facilitadores. O produto, que é turístico mas também é cultural, requer atenção em iniciativas várias: eventos temáticos, como a dramatização de cenas históricas em dias e locais específicos; espetáculos de luz e som e muitos outros, que são didáticos e agregam valor ao produto.

Pela cultura política brasileira, muito se espera pelos recursos federais e estaduais, numa era de mudanças, em que cada vez mais a localidade terá em suas mãos as responsabilidades e as oportunidades de mudanças, seja pela legislação e gestão próprias, seja pelo poder de pressão sobre as outras esferas do poder, uma vez que o município estiver bem gerido e a sociedade civil bem organizada.

\section{Referências Bibliográficas}

BONIFACE, Priscila. 1995. Managing quality cultural tourism. London and New York: Routledge. BORG, Jan van der. 2001. Gestão de turismo em Veneza ou como lidar com o sucesso. In: TYLER, Duncan et al. Gestão de turismo municipal. São Paulo: Futura.

CONSTITUIÇĀO da República Federativa do Brasil. 1988. São Paulo: Atlas.

ECO, Umberto. 1976. Tratado geral de semiótica. São Paulo: Perspectiva.

HERBERT, David T. 1995. Heritage, tourism and society. London: Mansell.

PIRES, Mário Jorge. 2002. Preservação é o desafio de Ouro Preto. O Estado de S. Paulo, São Paulo, 22 out. Caderno Viagem.

PRENTICE, Richard. 1995. Tourism and heritage attractions. London and New York: Routledge. WALLE, Alf H. Cultural tourism. 1998. [S.1.]: Westview Press.

Recebido em 13/08/2003.

Aprovado em 21/08/2003. 